City University of New York (CUNY) CUNY Academic Works

2015

\title{
Youth and parental perspectives on the functional family therapy programme
}

Katarzyna Celinska

CUNY John Jay College

Cherng-Cheng Chia

Rutgers University - New Brunswick/Piscataway

Nikiesha J. Virgil

Bloomfield College

\section{How does access to this work benefit you? Let us know!}

More information about this work at: https://academicworks.cuny.edu/jj_pubs/287

Discover additional works at: https://academicworks.cuny.edu

This work is made publicly available by the City University of New York (CUNY).

Contact: AcademicWorks@cuny.edu 


\title{
Youth and parental perspectives on the functional family therapy programme
}

\author{
Katarzyna Celinska ${ }^{\mathrm{a}}$, Chia-Cherng Cheng $^{\mathrm{b}}$ and \\ Nikiesha J. Virgil ${ }^{c}$
}

\begin{abstract}
Assessing clients' satisfaction with family therapy interventions has important practical and theoretical implications. This article presents findings on client satisfaction after participating in functional family therapy (FFT), which addresses youths at risk of delinquency behaviour and communication problems in the family. Qualitative interviews and quantitative research methods are employed to compare programme perceptions with standardized therapeutic outcomes. The data include a parent or guardian interview, a youth interview, a services tracking form and the initial and discharge strengths and needs assessment (SNA). We observed high levels of satisfaction with FFT, yet satisfaction with family therapy and therapists was higher among parents. Parents uniformly indicated satisfaction on six Likert scale items while the youths were satisfied only on one. We found five significant differences between the parents' and youths' responses. The parents reported greater trust in therapists, more engagement in family therapy and more positive perception of changes in family dynamics following the intervention. The two scales, satisfaction with the programme and satisfaction with the therapists, were correlated only for parents. However, both scales were correlated with some items on our outcome variable: the changes in the SNA, for parents and young people. We assessed predictors of satisfaction and found that satisfaction with therapy was inversely related to the number of sessions for youth. For parents, the only common predictor of both satisfaction with the therapist and satisfaction with the programme were the changes on the caregivers' strengths scale. The answers to the open-ended questions indicated that, although both parents and adolescents valued the improvements in communication patterns, the youth seemed to be especially attuned to changes in this area. Researchers should continue assessing satisfaction with family therapy and study the relationship
\end{abstract}

a Assistant Professor, John Jay College of Criminal Justice, Department of Law, Police Science and Criminal Justice Administration, 524 West 59 $9^{\mathrm{TH}}$ Street, 422:32, New York, NY 10019, USA. E-mail: kcelinska@jjay.cuny.edu.

b Data System Coordinator, Violence Institute at Rutgers University, NJ.

c Adjunct Lecturer, Division of Social and Behavioral Sciences, Bloomfield College, Bloomfield, NJ. 
between satisfaction and the intervention's outcomes. Our findings suggest also the importance of including youth in assessing satisfaction.

\section{Practitioner points}

- Assessing feedback from both, parents and youth, during and after an intervention can assist in providing more effective treatment.

- Youth might benefit from a shorter therapy and those who are mandated should be given more voice in an intervention.

- The strengths and needs assessment is a clinical tool that is useful in evaluating the intervention's outcomes.

- Functional family therapy improves communication skills among family members.

Keywords: functional family therapy; programme evaluation; satisfaction interviews; family therapy; youth and parental perspectives; youth delinquency.

\section{青少年与父母对于功能性家庭治疗项目的看法}

摘要：在家庭治疗干预中, 对于案主的满意度评估具有重要的理论和实践 意义。本文列出了案主在参与功能性家庭治疗(FFT)后的满意度调查结果, 该治疗是针对有潜在犯罪行为和家庭沟通障碍风险的青少年。研究应用了 定性访谈和定量研究方法, 参照常模来与调查情况相比照。每组数据包括 一次家长或监护人访谈、一次青少年访谈、服务跟踪表格和初始/结案时的 能力与需求评估(SNA)。研究显示, 功能性家庭治疗 (FFT) 拥有较高的满 意度,但父母对于家庭治疗和治疗师的满意度相对更高。父母在6个李克特 量表维度上都表现出了满意, 而青少年只在 1 个维度表现出了满意。父母和 青少年的回应在 5 个维度存在较为显著的差异。父母对治疗师表现出更多的 信任,在家庭治疗中参与程度更高, 对干预后家庭互动的改变持更为积极的 看法。“对项目的满意度” 和 “对治疗师的满意度”两个指标，只在父母 组存在相关关系。然而, 这两个指标都与能力与需求评估（SNA）中作为 效果变量的几个变量存在相关关系, 对于父母和青少年均如此。研究发 现，对治疗的满意度与青少年参与治疗次数成负相关关系。对于父母来 说, 作为照料人的能力变化是唯一能够同时预测对项目和治疗师的满意度 的变量。开放式问题的答案显示,尽管父母和青少年都重视沟通模式的改善, 青少年似乎尤为关注这方面的变化。研究者应继续评估家庭治疗的满意 度, 并进一步研究满意度和干预效果之间的关系。同时, 对于青少年的满 意度评估也应得到重视。

\section{临床应用要点}

- 对于父母和青少年进行干预中和干预后的双重评估有助于提供更有 效的治疗。

- 青少年更易从短程治疗中受益, 被要求参与治疗的青少年应在干预中 拥有更多的发言权。

- 能力与需求评估 (SNA) 能够有效的评估临床干预的效果。

- 功能性家庭治疗可提升家庭成员之间的沟通技巧。 
关键词：功能性家庭治疗；项目评估；满意度访谈；家庭治疗；青少年和 父母的观点；青少年犯罪。

\section{Introduction}

Functional family therapy (FFT) is an intervention for adolescents with behavioural problems and their families. This article presents findings on client satisfaction assessed after they had participated in FFT. Measuring clients' satisfaction is often viewed as an important indicator of programme effectiveness and service quality (Loff et al., 1987; Garland et al., 2007). Modality-specific indicators of clients' satisfaction can inform providers and therapists about strengths and weaknesses of the programme. Interviews with clients may also be useful for assessing the concordance between the programme design and the programme implementation. Client satisfaction data can inform the decisions of funding and accreditation agencies (Tilbury et al., 2010). Numerous public and private service sector providers even mandate consumer satisfaction assessments (Garland et al., 2000a). However, studies suggest that fewer than 10 per cent of mental health programmes include some type of satisfaction outcome (Garland et al., 2007).

Assessing programme satisfaction for family therapy is relatively complicated because it requires gauging and somehow combining the perceptions of both parents or guardians and their children (Sheridan et al., 2010; Walker, 2001). Perhaps owing to this complexity, as well as the difficulty of conducting research with children, few studies include feedback from young people; most research focuses exclusively on parents (DeRoche and Lahman, 2008; Garland et al., 2000b, Young et al.,, 1995). As DeRoche and Lahman (2008) indicated, in general children and adolescents tend to be marginalized in the mental health services. However, obtaining and analysing feedback from all family members who participate in therapy is very important because some research outcomes suggest that adolescents' and parents' perspectives on treatment often diverge (Aarons et al., 2010).

Post-programme satisfaction can have important implications for clients. Research suggests that programme satisfaction improves clients' retention while promoting more serious compliance with therapy and future therapeutic recommendations (Dearing et al., 2005). Finally, clients may find the experience of participating in satisfaction surveys or interviews as, itself, empowering (Tilbury et al., 2010). This process gives voice to those participants who had little say 
in their participation, whether because participation was courtordered or because they are minors (Tilbury et al., 2010; Spiro et al., 2009).

\section{Literature review}

Assessing client satisfaction is a fairly recent trend that started in $1970 \mathrm{~s}$ and was led by consumer advocates and feminists. It was fuelled by the first evaluation studies, which showed discrepancies between clients' satisfaction levels and their expectations, and an inadequate quality of services (Tilbury et al., 2010).

The first studies on family interventions to incorporate satisfaction ratings focused exclusively on feedback from parents. Traditional family therapy seemed to treat children as the objects of treatment rather than its participants(Strickland-Clark et al., 2000). Adolescents and children were viewed as incapable of forming coherent opinions, in part because of their limited language or communication skills. Their answers tend to be short and without the adequate contextual information that adults can provide (Tilbury et al., 2010).

However, in recent years, the proper measurement of children's perspectives has become imperative as researchers have recognized genuine disparities between the views of parents and children. A number of studies have measured satisfaction with mental health and family therapy among both parents and children (Aarons et al., 2010; Sheridan et al., 2010).

There are several relevant theories and concepts that directly apply to the client satisfaction assessment such as: the theory of cognitive dissonance, social desirability theory, global satisfaction and positive response bias. Researchers and practitioners identify two main interconnected theories on client satisfaction: cognitive dissonance and social desirability. The theory of cognitive dissonance links satisfaction levels with clients' perceived role in seeking services (Garland et al., 2000b). Clients, including adolescents, who believe that participating in intervention was voluntary, are more likely to be satisfied with the programme.

On the other hand, the theory of social desirability claims that pre-intervention motivation is the key to clients' satisfaction (Aarons et al., 2010). This theory can be especially applied to parents of adolescents participating in the intervention, who are particularly invested in their children's success (Young et al., 1995). Parents wish for the intervention to bring positive effects and that intent can 
affect their perception of the programme's effectiveness (Spiro et al., 2009).

Both theories are constructed on two concepts that can be derived from satisfaction data: a positive response bias and a high level of global satisfaction. High levels of global satisfaction mean that positive answers are predominant and that there is a low level of variability (Young et al., 1995). A positive response bias represents a general tendency to provide positive answers to satisfaction questions. One reason for this phenomenon is a client's desire to please the interviewer (Spiro et al., 2009).

Overall, prior studies found a high level of satisfaction for both parents and young people (Barber et al., 2006; Hennessy, 1999; Loff et al., 1987). Researchers agree that both factors impact on expressed satisfaction with the interventions. While the presence of these phenomena may skew or complicate the measurement of satisfaction, certain recommended procedures may help reduce their distorting impact (Garland et al., 2000b). We followed several such recommendations. Firstly, the interviews with the clients were conducted by researchers whom the families had never met. Secondly, the participants were assured that their answers were being used for research purposes only and would not be shared with the therapists or other programme staff. In short, they were promised full confidentiality and anonymity in all reports.

Given that client satisfaction is an important component of programme outcome, it is also pertinent to examine the predictors of satisfaction. Demographic variables are frequently tested but rarely prove to be good predictors of satisfaction (Garland et al., 2000a, 2000b). More strongly predictive are aspects of the intervention such as practical issues, the characteristics of the intervention and the characteristics of therapists. For example, a longer treatment duration and whether therapy was provided at the client's residence are both positively related to satisfaction (Garland et al., 2000a). Young et al. (1995) find that only parents' satisfaction is positively related to the number of sessions, while only adolescents' satisfaction is positively related to therapists' years of experience. Adolescents who feel that they were involved in seeking services are more likely to be satisfied with the programme (Barber et al., 2006; Garland et al., 2000b).

Most studies report high satisfaction levels for both parents and their children following participation in family therapy (Garland et al., 2000a, 2007). However, young people are typically less satisfied with the services than their caretakers (Barber et al., 2006). In addition, 
there are mixed results in the concordance between the perceptions of satisfaction of the parents and that of their children (Garland et al., 2000a, 2007). One study found that young people and parents tend to focus on different aspects of the programme (Garland et al., 2000a). As a result, convergent satisfaction scores for parents and children are often difficult to interpret. Finally, one of the main goals of satisfaction studies is investigating a potential correlation between satisfaction and outcomes. However, studies have shown mixed results with regards to the relationship between client satisfaction and success outcomes (Garland et al., 2000a, 2003).

\section{Functional family therapy}

In this study we assessed satisfaction among parents and their children after their participation in FFT. This intervention was provided to families by the Children at Risk Resources and Interventions Youth Intensive Intervention Program (CARRI-YIIP) at the University of Medicine and Dentistry of New Jersey (currently, Rutgers University). FFT is a therapeutic intervention designed for delinquents and minors at risk of delinquency aged 11 to 17 years and their parents (Sexton and Alexander, 2004).

FFT is a short-term (generally lasting 3 months) and highly structured intervention. It consists of three phases: engagement and motivation, behavioural change and generalization. During engagement and motivation the therapist works on building an alliance with the family members and on reducing negativity. During the behavioural change phase the therapist works on changing the behaviour of adolescents and their family members that has led to conflict and delinquency. The therapist typically focuses on parental, problem-solving and conflict management skills. During the generalization phase families learn how to sustain positive changes and how to utilize available community resources (Sexton and Alexander, 2004).

The FFT therapists have to complete special intensive trainings before they start seeing any families. They are continuously trained, supervised and monitored for their fidelity to the FFT model through offsite, Web-based supervision (Sexton and Alexander, 2004).

We found only one study measuring satisfaction with FFT (Holm-Hansen, 2008). This study involved conducting surveys with twenty-seven youths and thirty parents. Both adolescents and parents positively assessed the programme and the therapists. When asked about the most positive aspects of FFT, both youth and parents 
mentioned improved communication and family relationships. Parents brought up positive changes in youth's behaviour due to FFT. Most youth did not want to change anything in the programme but a few would have preferred shorter and less frequent sessions. The parents were content with FFT and did not suggest any need for improvements. These results, based on a small sample of participants, suggest there is a need for more in-depth studies on satisfaction with FFT.

\section{Aims of current study}

This article presents findings on youth and parents' satisfaction assessed after participating in FFT. This study contributes to scholarly research and to practice in several ways. Firstly, in contrast to many studies on client satisfaction, our research assessed feedback not only from parents but also from adolescents. Specifically, we compared young people and parents' perceptions of FFT. Collecting data from multiple sources enhances the validity of our satisfaction outcomes. Secondly, our sample of 147 participants is large enough to permit the application of both qualitative and quantitative research methods; an approach recommended by many researchers in the field (McWey et al., 2011). Thus, we employed both a standardized measure of satisfaction and open-ended questions. Next, we examined the strength of the association between client satisfaction and therapeutic outcomes - the changes in the clients' and their guardians' risks and strengths as measured by the strengths and needs assessment (SNA). Finally, this study contributes to substantive knowledge on the specific strengths and challenges of FFT; an intervention that is widely applied and supported by the number of governmental and non-governmental institutions such as the Office of Juvenile Justice and Delinquency Prevention (Alexander and Sexton, 2002). The feedback provided by the clients can guide future implementation efforts as policy-makers seek to accommodate and address the strengths of the FFT programme and the concerns of the participants.

To summarize, the four main goals of this study are: (i) to determine satisfaction of adolescents and parents with FFT and with the therapists, (ii) to test for an association between therapeutic improvements and treatment satisfaction, (iii) to assess predictors of satisfaction, and (iv) to analyse open-ended questions to contextualize quantitative results. 
Data and methods

This project was a part of a larger evaluation study conducted by the first author. The main research project was a multi-year outcomebased evaluation with a pre-post comparison group design. The project was approved by the appropriate institutional review boards.

\section{Participants}

In this study there were 147 participants, sixty-nine adolescents and seventy-eight guardians. In nine cases both parents participated in the intervention and the post-programme interview. This analysis included only the cases with all data elements: a parent or guardian interview, a youth interview, a services tracking form (STF) and the initial and discharge SNAs. From a full sample of 202 we excluded fifty-five cases because the interviews were not completed or the cases had incomplete data. In addition, due to a reduction in research staff, in nine cases the families filled out the questions on their own instead of being interviewed.

The sample of adolescents included thirty-nine male and thirty female clients with an average age of 15 years. Of the participants, twenty-two were White, twenty-three Black, seventeen Latino and seven were of mixed race. These data came from the SNA. Based on the STF, among the sixty-nine adolescents, forty-one (nearly 60 per cent) were mandated by the family court to participate in FFT. Table 1 provides the profile of the sample of young clients.

\section{Method}

We utilized a triangulation research methodology that entails both qualitative and quantitative methods. Qualitative measures allow for a more nuanced and situated assessment (Aarons et al., 2010; Barber et al., 2006). Some researchers indicate that the qualitative openended questions provide a better resource for clients to express their dissatisfaction with the programme than the standardized tests (Perreault et al., 1993). In addition, unstructured open-ended questions seem to be particularly advantageous for assessing the satisfaction of adolescents (Tilbury et al., 2010).

\section{Instruments}

In order to assess clients' perceptions of their treatment and to link their satisfaction with therapeutic outcomes we combined several 
TABLE 1 Characteristics of the youth sample $(\mathrm{N}=69)$

\begin{tabular}{llr}
\hline Participants' characteristics & $N(\%)$ \\
\hline Gender & Male & \\
& Female & $39(56.5)$ \\
Race/ethnicity & & $30(57.5)$ \\
& White & $22(29.0)$ \\
& Black & $23(33.3)$ \\
& Latino & $17(24.6)$ \\
Age (years, SD) & Other & $7(10.1)$ \\
Sessions attended & & $15.1(1.5)^{*}$ \\
Sessions missed & & $14.4(5.5)^{*}$ \\
Services mandated & Yes & $3.9(3.2)^{*}$ \\
Referral & & $41(59.4)$ \\
& Middlesex County Probation & $28(40.6)$ \\
& Middlesex County Multi-Disciplinary Team & $1(1.4)$ \\
& Division of Youth and Family Services & $5(7.2)$ \\
& Family Crisis Intervention Unit & $7(10.1)$ \\
& Youth Case Management & $7(10.1)$ \\
& Mobile Response & $10(14.5)$ \\
& Other & $11(15.9)$ \\
\hline
\end{tabular}

Note: *Average number (standard deviation).

different data sources: the interviews with the parents, the interviews with the young clients, the SNA and the STF. The interview included both open-ended questions and a series of statements with a response set on a five-point Likert scale. The Likert scale items focused on the relationship with the therapist (thirteen items) and on satisfaction with the programme (ten items). The eight open-ended questions gauged overall impressions and asked about the most and the least liked features of the programme. The questions were developed by the first author.

The quantitative questions were developed by Tolan et al. (2002), who conducted two studies using a sample of 187 racially diverse families with children aged 8-17 years. The first study factor-analysed six sub-scales to measure, among others, satisfaction with the therapist and the programme. As a result, the authors developed instruments for children and parents to rate their satisfaction or alliance with family interventions. According to the authors, the designed scales are robust, reliable (they replicated their findings with a second study on a different sample), brief, with discriminant and convergent validity and sensitive to individual differences. 
The SNA is a therapeutic and an evaluation tool developed by Lyons (2009; Lyons et al., 2004). It is a slightly revised version of the child and adolescent needs and strengths assessment (CANS) (Lyons et al., 2004). Research on CANS and SNA indicates that they exhibit face, construct, concurrent and predictive validity and show good interrater and auditor reliability (Anderson and Estle, 2001; Anderson et al., 2003; Lyons, 2009; Lyons et al., 2004). The reliability of the SNA was also assured in this project via training and a review of client records. The CARRI-YIIP therapists were certified in the use of SNA via training, either by participating in person or by participating through a secure Internet site. The training included scoring vignettes of real cases (Caliwan and Furrer, 2009).

The SNA consists of seven dimensions: life domain functioning, child strengths, acculturation, caregiver strengths, caregiver needs, child behavioural or emotional needs, and child risk behaviour. The youth and the caregivers were rated by the therapists on each item in each domain on a scale ranging from zero (no evidence of problem) to three (severe; need and priority for an intervention). Based on the SNA domains we created six scales: the life domain scale (LDS), the child strengths' scale (CS), the caregivers' strengths' scale (CSS), the caregiver needs scale (CNS), the child behavioural and emotional needs scale (CBEN), and the child risk behaviour scale. These scales were previously utilized in an FFT outcome evaluation study of a sample of seventy-two youths and their parents (Celinska et al. 2013).

The STF is a tool designed by the first author in collaboration with the therapists to gather basic information about the clients' pretreatment experience (for example, referral sources and household size) and treatment logistics (the number of sessions, the length of participation). It provides supplementary data used in the analysis. It is a record-keeping, not a clinical, tool, although the therapists also rated the clients' overall change in adolescents' behaviour (on a simple Likert scale of one to four).

\section{Procedure}

The SNA was conducted at the beginning and at the end of the intervention. The therapists filled out the SNA based on clients' records, their own assessment and the interview with the family. The STF was filled out by the therapists in the beginning (for example, referral source) and completed at the end of the therapy (for example, the number of sessions attended). 
The interviews in this project were conducted during the final FFT sessions. In the beginning of the interview the participants were reminded that their participation in this study was voluntary, confidential and anonymous, and that their comments would not be shared with their therapists. The guardians and children were interviewed separately. One interview took on average 20 minutes. The interviews were tape-recorded (excluding six cases) and later on, transcribed by the research team.

\section{Results}

This section is divided into four parts. Firstly, we present the results of the Likert scale questions on satisfaction with the programme and with the therapists, and on comparing youth and their guardians' perceptions. Secondly, we examine the correlation between satisfaction, derived from the Likert scale satisfaction questions with the needs and strengths derived from the SNAs. Thirdly, we assess predictors of satisfaction. Fourthly, we discuss the results of the openended questions.

\section{Satisfaction with the programme and the therapists}

The clients of FFT were asked to rate their relationship with the therapist and satisfaction with the programme on a five-point Likert scale. All the results are presented in Table 2.

Consistent with previous literature, the most of the items received uniformly high scores, indicating high satisfaction with the performance of the therapists and with the intervention itself. All guardians strongly agreed that: the therapist has shown us respect, I trust the therapist, I believe that the therapist was helping us, the therapist cared about my goals for myself and my child, I like the therapist and I have gotten some helpful ideas about my family. On the other hand, sampled adolescents uniformly strongly agreed with only one statement: the therapist seemed well organized. Chi-squares uncovered five significant differences between the scores of guardians and their children. Relative to their children, the guardians reported greater agreement with following items: I trust the therapist, I have gotten some helpful ideas about my family, since being in this programme, I feel better about my family problems, I usually looked forward to the next session and even though I have been frustrated, I have kept on trying to achieve my goals. The first and the fourth 
TABLE 2 Satisfaction with the programme and therapist as measured on Likert scale questions from strongly agree (5) to strongly disagree (1)

\begin{tabular}{|c|c|c|c|}
\hline Questions on relationship with the therapist & $\begin{array}{l}\text { Youth } \\
(\%)\end{array}$ & $\begin{array}{l}\text { Guardian } \\
\quad(\%)\end{array}$ & $\chi^{2}$ test \\
\hline The therapist has shown us respect & 97.1 & 100 & 2.292 \\
\hline The therapist likes me & 95.6 & 97.4 & .357 \\
\hline I trust the therapist & 89.9 & 100 & $8.309 * *$ \\
\hline I believe that the therapist was helping us & 97.1 & 100 & 2.292 \\
\hline The therapist seemed well organized & 100 & 98.7 & .891 \\
\hline The therapist understood me & 91.2 & 94.9 & .778 \\
\hline The therapist was easy to understand & 92.8 & 98.7 & 3.327 \\
\hline $\begin{array}{l}\text { The therapist cared about my goals for } \\
\text { myself and my child }\end{array}$ & 95.4 & 100 & 3.677 \\
\hline $\begin{array}{l}\text { The therapist has helped us keep on track } \\
\text { with our goals in the programme }\end{array}$ & 91.2 & 97.4 & 2.685 \\
\hline The therapist really helped us & 89.9 & 94.9 & 1.331 \\
\hline Do you like the therapist? & 97.1 & 100 & 2.292 \\
\hline $\begin{array}{l}\text { Did you feel comfortable telling [name] } \\
\text { things that were hard to say? }\end{array}$ & 84.1 & 94.7 & $4.447 *$ \\
\hline $\begin{array}{l}\text { Did you feel safe talking to the therapist } \\
\text { about your fears? }\end{array}$ & 89.2 & 89.6 & .005 \\
\hline \multicolumn{4}{|l|}{$\begin{array}{l}\text { Questions on satisfaction with the } \\
\text { programme }\end{array}$} \\
\hline I am satisfied with the programme & 89.9 & 94.9 & 1.331 \\
\hline $\begin{array}{l}\text { I believe that the programme was helping } \\
\text { my family }\end{array}$ & 85.5 & 94.9 & 3.726 \\
\hline $\begin{array}{l}\text { I have gotten some helpful ideas about my } \\
\text { family }\end{array}$ & 94.2 & 100 & $4.648^{*}$ \\
\hline $\begin{array}{l}\text { Since being in this programme, I feel better } \\
\text { about my family problems }\end{array}$ & 76.1 & 90.9 & $5.839 *$ \\
\hline $\begin{array}{l}\text { The problems we face in life are much } \\
\text { better now }\end{array}$ & 82.6 & 91 & 2.305 \\
\hline $\begin{array}{l}\text { In the programme, I have tried hard to } \\
\text { improve }\end{array}$ & 91.3 & 97.4 & 2.675 \\
\hline I usually looked forward to the next session & 63.8 & 86.7 & $10.242 * *$ \\
\hline $\begin{array}{l}\text { Even though I have been frustrated, I have } \\
\text { kept on trying to achieve my goals }\end{array}$ & 89.7 & 98.7 & $5.514^{*}$ \\
\hline
\end{tabular}

Note: * significant at $>0.05$; **significant at $>0.01$. The interview questions came from Tolan $e t$ al. (2002). 'The youth version was 'The therapist cared about my goals for me and my family'.

items are significant at 0.001 while the other items are significant at the 0.05 level.

Next, a factor analysis of the satisfaction items yielded four factors: the relationship between the therapist and the adolescents (thirteen items, alpha $=0.927)$, the relationship between the therapist and the 
guardian (thirteen items, alpha $=0.915$ ), youth satisfaction with the programme (eight items, alpha $=0.879$ ) and guardian satisfaction with the programme (eight items, alpha $=.870$ ). As expected, there is a significant correlation between parent-therapist and youth-therapist satisfaction $(\mathrm{r}=.292$ at $P<0.05)$ and between parent-programme and youth-programme satisfaction $(\mathrm{r}=.412$ at $P<0.001)$. An additional $t$-test of differences between young people and guardians indicated that guardians were statistically more satisfied with the programme than the youth $(t=-3.67$ at $P<0.001)$.

\section{Relationship between satisfaction and the therapy outcomes}

Firstly, we conducted a correlation analysis between the four factors discussed above, changes in the SNA domains and a set of variables from the STF. We report here only statistically significant relationships. For the children, the relationship with the therapist has a positive correlation with the LDS $(\mathrm{r}=.286$, significant at $P<0.05)$, CBEN $(r=.262$, significant at $P<0.05)$ and the therapist's rating of positive changes in adolescents $(\mathrm{r}=.396$, significant at $P<0.01)$. Satisfaction with the programme correlated positively with the LDS ( $\mathrm{r}=.343$, significant at $P<0.01)$ and the positive changes in adolescents as rated by the therapist $(\mathrm{r}=.418$, significant at $P<0.01)$. For the guardians, the relationship with the therapist correlated with the CSS $(\mathrm{r}=.336$, significant at $P<0.01)$ and the CNS $(\mathrm{r}=.240$, significant at $P<0.05)$. Satisfaction with the programme had a positive relationship with the CSS $(\mathrm{r}=.452$, significant at $P<0.01)$, the length of the programme $(\mathrm{r}=.252$, significant at $P<0.05)$, the number of sessions $(\mathrm{r}=.234$, significant at $P<.05)$ and the changes in adolescents as rated by the therapists $(\mathrm{r}=.448$, significant at $P<0.01)$.

The relationship between satisfaction with the programme expressed by the young people and the parents and the positive changes in adolescents as rated by the therapists is important because it suggests that the therapists' perception of improvements is related and is validated by the clients' programme satisfaction.

\section{Predictors of satisfaction}

Next, we identified the predictors of satisfaction with the therapy and the therapists. We estimated models of the relationship with the therapist and with the satisfaction as a function of: age, length of the programme, number of sessions, gender, race, ethnicity, whether the 
services were mandated, and the four scales LDF, CS, CBEN and CR, using ANCOVA. The choice of variables was based on the prior literature and the outcome variables that were correlated with the satisfaction measures. See Table 3 for selected results only.

We found that the only significant predictor of satisfaction with therapist for young people was the number of sessions. Surprisingly more sessions predicted less positive feelings about their relationships with their therapists. Next, we conducted the same analysis for the guardians. The relationship with the therapist was significantly and positively predicted by the CSS. Similarly, the CSS was a significant and positive predictor of satisfaction with the programme.

\section{The analysis of the open-ended interview questions}

To provide further insight into satisfaction with FFT and the programme, and the therapists we analysed responses to the open-ended questions. We employed an inductive approach to our data analysis, based on grounded theory (Glaser and Strauss, 1967). Our method involved reading transcripts and analysing emerging themes from the data. However, the analysis was influenced by the format of the questions (general questions) and by the research protocol (no follow-up questions). Nonetheless, the results provide an important context to our quantitative analysis.

TABLE 3 Four models: relationship with therapist and satisfaction with the programme for youth $(\mathrm{N}=69)$ and parents $(\mathrm{N}=78)$. Only significant and near-significant results of ANCOVA are presented.

\begin{tabular}{|c|c|c|c|c|c|c|}
\hline Sample & Dependent variable & $\begin{array}{l}\text { Independent } \\
\text { variable }\end{array}$ & B & $\mathrm{SD}$ & $\mathrm{t}$ & Sig \\
\hline Youth & $\begin{array}{l}\text { Relationship with } \\
\text { therapist }^{1}\end{array}$ & Sessions $(n)$ & -.044 & .016 & -2.703 & .009 \\
\hline \multirow[t]{4}{*}{ Youth } & \multirow[t]{4}{*}{$\begin{array}{l}\text { Satisfaction with } \\
\text { programme }\end{array}$} & Sessions $(n)$ & -.038 & .022 & -1.696 & .096 \\
\hline & & White & .503 & .298 & 1.689 & .098 \\
\hline & & Black & .597 & .292 & 2.046 & .046 \\
\hline & & LDS & .868 & .409 & 2.125 & .039 \\
\hline \multirow[t]{2}{*}{ Parents } & \multirow{2}{*}{$\begin{array}{l}\text { Relationship with } \\
\text { therapist }^{3}\end{array}$} & CAS & .311 & .111 & 2.790 & .007 \\
\hline & & CNS & .497 & .263 & 1.890 & .063 \\
\hline Parents & $\begin{array}{l}\text { Satisfaction with } \\
\text { programme }\end{array}$ & CAS & .524 & .134 & 3.923 & .000 \\
\hline
\end{tabular}

Note: $\mathrm{R}_{1}$ squared $=.380, \mathrm{R}_{2}$ squared $=.302, \mathrm{R}_{3}$ squared $=.201, \mathrm{R}_{4}$ squared $=.270$. CAS, caregivers' strengths' scale; CNS, caregivers' needs scale; LDS, life domain scale. 
Both parents and their children were asked to describe what it was like to be in the programme. Just over 20 per cent of adolescents and 20 per cent of adults used positive adjectives to describe their overall experience. Favoured adjectives used by the young people were good, fun, nice, cool, interesting, different, while typical adjectives used by the guardians were enjoyable, pleasurable, fun, different and exciting. Most guardians (over 60 per cent) focused their answers on the outcomes of FFT, such as knowledge acquired and improved communication among family members. One mother (son, aged 17) said:

I learned better communication skills. I learned to become a little bit more understanding because, maybe, what is so important to me may not be so important to the other person.

A substantial share of responses to this question focused on therapists. One young woman (aged 14) described the importance of her therapist in facilitating more open communication with her mother:

OK. I didn't get to say this at home but I can say it in the session because I know the counsellor is going to stop her (mom) from, you know, interrupting me.

Both groups were asked what they liked the most about the programme. Nearly all the parents liked the fact that the therapy provided a comfortable venue for their families to talk, to discuss and to solve the problems. It seems that a similar notion was conveyed by a smaller number of adolescents. Just over 35 per cent of young people liked the fact that they had an opportunity to talk about the problems they have at home and at school. One young man (aged 17) said:

But doing this programme, if we were mad or someone had seen us mad we could just talk about it. People could talk about their problems. I know like most kids my age they don't want to talk about their problems, they want to deal with it themselves but it's better to talk out your problems than just hold them in.

In total 30 per cent of the adolescents liked the help they received. Relative to those of their children, the valuations of parents apparently place more weight on the characteristics of the therapist. An equally sizable portion of parents mentioned therapeutic outcomes in response to this question, especially the improvements in communication among their family members. One parent (two sons, aged 16) related improvements in communication to positive outcomes more generally: 
It was well needed and it gave the kids a chance to communicate outside of what was going on in the family. I think that if we didn't have it I don't know where we would be today. We kept going because I liked the fact that I saw a change in them. They were changing. They were opening up.

Another parent (son, aged 17) tied improved communication to increased closeness:

What I liked most is that it helped my family. It helped us to learn how to talk to each other. It helped me as a parent to have a better relationship with my kids ... I learned to be a disciplinarian and friend at the same time; it helped us to talk more and to get closer.

Finally, the participants were asked what they liked the least about being in the programme. Over 35 per cent of adolescents indicated that they did not like coming to the therapy, which bespeaks a level of dissatisfaction that is not evident from the satisfaction scores. Some thought that the therapy was boring, while others complained that therapy left them with less time for their friends and leisure activities. The young people also complained about long hours sitting on the chair, the onerous travel distance and the strain of discussing their personal difficulties in front of family members.

Whereas many young people complained about aspects of the therapy itself, the parents directed their criticism at logistical issues. Nearly 20 per cent of parents described obstacles and inconveniences, such as unreliable transportation to the programme, the long drive from home or work and the inconvenience of the therapy times. Other issues mentioned by a small number of parents included the therapy location (with a preference expressed for home), the need for separate sessions for siblings, the emotionally taxing first sessions and there being too many documents to fill out. Finally, six parents stated that they did not find the programme helpful. Two of these parents explained that the therapy was probably not long enough to have a positive impact.

\section{Discussion}

The first goal of our study was to assess the satisfaction of youths and their parents with FFT. Consistent with prior research on satisfaction with family therapy and mental health interventions, we observed high levels of satisfaction with FFT. We found that most responses on both the Likert scale and the open-ended questions were very positive towards both the programme and the therapists. Although this 
pattern was evident among both parents and their children, as in prior studies, the parents showed more satisfaction with the intervention. In fact, the parents uniformly indicated satisfaction on six Likert scale items, while the young people agreed only on one satisfaction item. This finding suggests the need to continue assessing opinions about participating in family interventions not only from adults but also from young participants.

We found five significant differences on the Likert scale items between parents' and their children's' responses. The parents' greater trust in the therapists could be due to social desirability bias when parents try to please researchers, assuming that positive answers would show their appreciation for the programme and led to a better programme evaluation. Another possible explanation is that the therapists developed a stronger alliance with the parents than with the young clients. However, we did not detect such a pattern from the open-ended questions. With respect to programme outcomes, the parents reported learning more ideas about their families and feeling better about their family problems. Overall, the young participants were less confident that the intervention had had a positive impact on their families. The parents also indicated that they had tried harder to achieve the goals in the therapy, perhaps reflecting a lower commitment to the therapy among the adolescents, especially the young people who were mandated by the court to participate in FFT. Finally, while the parents agreed that they were looking forward to the next session, many adolescents did not. This assertion was also evident from our analysis of open-ended questions. The interviews suggested that boredom was a big factor.

Our findings also suggest that the parents' valuations of FFT give more weight to the characteristics of therapist. Specifically, satisfaction with the therapist and with the programme were correlated only among the parents. This finding suggests again the importance of assessing differences in satisfaction between parents and their children.

Next, we addressed the second goal of our study: the relationship between satisfaction and the therapy outcomes. We found that the youth's ratings of therapists were correlated with the changes in the LDS, changes in the CBEN scale and the therapists' ratings of their progress. Youth satisfaction with the programme was correlated with improvements in the LDS and in therapists' ratings of adolescents' progress. A logical interpretation is that youths who experienced more positive changes are more likely to see the programme as helpful. 
Correspondingly, parents' satisfaction with the therapists and with the programme were positively correlated with the changes in the CSS. Parental satisfaction with the programme was also correlated with the length of the programme, number of sessions and changes in youth as recorded by the therapists. Again, this shows that parents who experience skills' enhancements and see improvements in their children's behaviour have more positive feelings about the programme and the therapist. Longer and more frequent therapy may be associated with greater parental programme satisfaction because it yields more gains. It is also plausible that parental assessments were biased by a subconscious belief that longer therapy should have more a positive impact.

Just as other researchers in the field have done, we conducted an analysis to find predictors of satisfaction (goal three of our research). Consistent with prior literature, demographic factors did not impact on satisfaction ratings. The only predictor of youth satisfaction with the therapists was the number of sessions. Interestingly, more sessions meant less satisfaction. Although it seems like a contradiction, this finding suggests that adolescents might be responding better to shorter interventions and therapies. For parents, the only common predictor of both satisfaction with the therapist and satisfaction with the programme were the changes on the CSS. Parents were more likely to be satisfied with the programme and with the therapist when they gained more knowledge about their children and improved their living arrangements and their access to social resources.

The use of open-ended questions contributes to our understanding of individual experiences in FFT. The analysis of open endedquestions (goal four of our study) affirms prior studies that suggest less enthusiasm for family therapy among adolescents than among their parents. We also found, as in some prior studies, that parents are more focused on logistics when evaluating the programme. When asked about the aspects of the programme they liked most, the largest group of young clients pointed to improved communication among family members and the parents tended to stress the impact of the programme on their children.

One limitation of the research is that satisfaction is not assessed among programme dropouts, which is likely to is likely to limit variation in satisfaction outcomes. Future research on satisfaction can remedy this problem by assessing satisfaction at multiple time points. Our analysis of open-ended questions provides a context to the quantitative analysis. However, the analysis was limited in part due to the 
format of the interview, which was brief and the questions focused on general perception of participating in the programme. Future research should include more open-ended questions and questions that are specifically designed to address the elements of a particular intervention. We also think that future studies should consider additional measures of satisfaction because the problems of global satisfaction and positive response bias can limit the researchers' abilities to conduct more thorough analyses.

Despite these limitations, this research deepens and refines our understanding of satisfaction with therapists and with family therapy, specifically with FFT. It suggests particular aspects of FFT that elicit differential evaluations from parents and children. We suspect that the children's lower levels of satisfaction are due in no small part to the fact that more than half of them were mandated to participate in FFT. Perhaps giving more voice to mandated participants in the intervention could lead to greater commitment and involvement on their part and possibly to more satisfaction with the programme.

In contrast to some of the prior studies this study shows that family therapy outcomes are related to clients' satisfaction. Our distinctive results may be conditioned by the nature of SNA - the tool that provided us with thorough information on changes in young clients and their parents' strengths and needs. Finally, based on open-ended questions we found that although the young people were more reluctant than their parents to participate in an intervention, they also seem at the same time to be more sensitive and attuned to changes in communication patterns among all family members. These findings affirm the importance of the central goal of FFT; improvements in interactions and communication among family members. More generally, adolescents are cognizant of therapeutic goals and their opinions of the programme are very valuable and could shed more light on how the programme is being delivered.

\section{Acknowledgement}

This research was supported in part by the PSC-CUNY TRADB-42673 Research Award. We would like to thank FFT families and the CARRI-YIIP therapists for participating in this study. Thanks to Rebecca Stewart, Research Assistant and a John Jay College student, for her work on the project and Paul Hirschfield for his assistance and advice. Finally, we would like to thank Editor Mark Rivett and our anonymous reviewers for their helpful comments and suggestions. 


\section{References}

Aarons, G. A., Glisson, C., Hoagwood, K., Landsverk, J and Cafri, G. (2010) Psychometric properties and United States national norms of the evidencebased practice attitude scale (EBPAS). Psychological Assessment, 22: 356365.

Alexander, J. F. and Sexton, T. L. (2002) Functional family therapy: a model for treating high risk, acting-out youth. In F. W. Kaslow (ed.) Comprehensive Handbook of Psychotherapy: Integrative/Eclectic, Vol. 4 (pp. 111-132). New York: John Wiley.

Anderson, R. L. and Estle, G. (2001) Predicting level of mental health care among children served in a delivery system in a rural state. Journal of Rural Health 17: 259-65.

Anderson, R. L., Lyons, J. S., Giles, D. M., Price, J. A. and Estle, G. (2003) Reliability of the child and adolescent needs and strengths-mental health (CANS-MH) scale. Journal of Child and Family Studies, 12: 279-289.

Barber, A. J., Tischler, V. A. and Healy, E. (2006) Consumer satisfaction and child behavior problems in child and adolescent mental health services. Journal of Child Health Care, 10: 9-21.

Caliwan, J. and Furrer, S. (2009) A statewide implementation of an information management and decision support system for children and families in New Jersey. In Lyons, J. S. and Weiner, D. A. (eds) Behavioral Health Care. Assessment, Service Planning, and Total Clinical Outcomes Management (pp. 525-531). Kingston, NJ: Civic Research Institute.

Celinska, K., Furrer, S. and Cheng, Ch. (2013) Evaluation of functional family therapy: a case of the CARRI-YIIP intervention. Journal of Juvenile Justice, 2: 223-236.

Dearing, R. L., Barrick, C., Dermen, K. H. and Walitzer, K. S. (2005) Indicators of client engagement: influences on alcohol treatment satisfaction and outcomes. Psychology of Addictive Behaviors, 19: 71-78.

DeRoche, K. K. and Lahman, M. K. E. (2008) Methodological considerations for conducting qualitative interviews with youth receiving mental health services. Forum: Qualitative Social Research, 9: 17-35.

Garland, A. F., Aarons, G. A., Saltzman, M. D. and Kruse, M. I. (2000a) Correlates of adolescents' satisfaction with mental health services. Mental Health Services Research, 2: 127-139.

Garland, A. F., Saltzman, M. D. and Aarons, G. A. (2000b) Adolescent satisfaction with mental health services: development of a multidimensional scale. Evaluation and Program Planning, 23: 165-175.

Garland, A. F., Aarons, G. A., Hawley, K. M. and Hough, R. L. (2003) Relationship of youth satisfaction with mental health services and changes in symptoms and functioning. Psychiatric Services, 54: 1544-1546.

Garland, A. F., Haine, R. A. and Boxmeyer, C.L. (2007) Determinates of youth and parent satisfaction in usual care psychotherapy. Evaluation and Program Planning, 30: 45-54.

Glaser, B. and Strauss, A. (1967) The Discovery of Grounded Theory: Strategies for Qualitative Research. Hawthorne, NY: Aldine.

Hennessy, E. (1999) Children as service evaluators. Child Psychology \& Psychiatry Review, 4: 153-161. 
Holm-Hansen, C. (2008) Functional family therapy satisfaction survey results. St Paul, MI: Amherst H. Wilder Foundation 2007-08 evaluation.

Loff, C. D., Trigg, L. J. and Cassels, C. (1987) An evaluation of consumer satisfaction in a child psychiatric service: viewpoints of patients and parents. American Journal of Orthopsychiatry, 57: 132-134.

Lyons, J. S. (2009) Communimetrics. A Communication Theory of Measurement in Human Service Settings. Dordrecht: Springer.

Lyons, J. S., Weiner, D. A. and Lyons, M. B (2004) Measurement as communication. The child and adolescent needs and strengths tool. In M. Mariush (ed.) The Use of Psychological Testing for Treatment Planning and Outcome Assessment, Vol. 2 (pp. 461-476). Mahwah, NJ: Lawrence Erlbaum.

McWey, L. M., Humphreys, J. and Pazdera, A. L. (2011) Action-oriented evaluation of an in-home family therapy program for families at risk for foster care placement. Journal of Marital and Family Therapy, 37: 137-152.

Perreault, M., Leichner, P., Sabourin, S. and Gendreu, P. (1993) Patient satisfaction with outpatient psychiatric services: qualitative and quantitative assessments. Evaluation and Program Planning, 16: 109-118.

Sexton, T. L. and Alexander, J. F. (2004) Functional Family Therapy Clinical Training Manual. Seattle, WA: Annie E. Casey Foundation.

Sheridan, M., Peterson, B. D. and Rosen, K. H. (2010) The experiences of parents of adolescents in family therapy: a qualitative investigation. Journal of Marital and Family Therapy, 36: 144-157.

Spiro, S. E., Dekel, R. and Peled, E. (2009) Dimensions and correlates of client satisfaction: an evaluation of a shelter for runaway and homeless youth. Research on Social Work Practice, 19: 261-270.

Strickland-Clark, L., Campbell, D. and Dallos, R. (2000), Children's and adolescents' views on family therapy. Journal of Family Therapy, 22: 324341.

Tilbury, C., Osmond, J. and Crawford, M. (2010) Measuring client satisfaction with child welfare services. Journal of Public Child Welfare, 4: 77-90.

Tolan, P. H., Hanish, L. D., McKay, M. M. and Dickey, M. H. (2002) Evaluating process in child and family interventions: Aggression prevention as an example. Journal of Family Psychology, 16: 220-236.

Walker, S. (2001) Consulting with children and young people. International Journal of Children's Rights, 9: 45-56.

Young, S. C., Nicholson, J. and Davis, M. (1995) An overview of issues in research on consumer satisfaction with child and adolescent mental health services. Journal of Child and Family Studies, 4: 219-238. 